\title{
EFFECT OF TRICHODERMA ON SEED GERMINATION AND SEEDLING PARAMETERS OF CHILI
}

\author{
M Asaduzzaman ${ }^{1}, \mathrm{M}$ J Alam ${ }^{2}$ and M M Islam ${ }^{3}$
}

\begin{abstract}
T. virens IMI-392430, T. pseudokoningii IMI-392431, T. harzianum IMI-392432, T. harzianum IMI-392433 and T. harzianum IMI-392434 were evaluated for their potentiality on seed germination and seedling parameters in chili both laboratory and field conditions. Chili seeds were coated with spore suspension of each test strains of Thichoderma supplemented with $2 \%$ of starch $(\mathrm{w} / \mathrm{v})$ as an adhesive. Seed germination percentages and the vigour index were significantly affected by the application of different strains of Trichoderma. Among the five Trichoderma strains, T. harzianum IMI-3924332 gave the highest germination percentage followed by T. harzianum IMI-3924333, T. harzianum IMI-3924334, T. virens IMI-392430 and T. pseudokoningii IMI-392431 treatment both in laboratory and field conditions, respectively while control decrease these value. Chili seeds also gave the highest vigour index values with T. harzianum IMI-3924332 which confirmed to better germination. Seed treatment with $T$. harzianum IMI-3924332 can be useful to enhance the germination of chili seeds as well as reduce to delayed germination. Further investigations however are required to study in vivo effect of Trichoderma strains on morphological and physiological characteristics in chili plant and fruit production.
\end{abstract}

Key word: Trichoderma $a_{2}$ spore suspension, germination percentages, vigour index, chili.

\section{INTRODUCTION}

Chili (Capsicum annuum L.) is one of the most important spice crops in the world and grown in all seasons and areas of Bangladesh. The average yield of chili is $0.042 \mathrm{tha}^{-1}$ which is very low as compared to the yield of other chili growing countries of the world (Anonymous, 2003). Delayed and erratic germination of chili seeds is one of the reasons of low yield of chili. There are many factors responsible for the delayed and erratic germination of chili seeds. Among the various factors diseases are predominant. Fungal diseases play a vital role in reducing the germination of chili. Water imbibitions are first step in the seed germination. But crop field may lack adequate moisture content for the same, so poor and delayed germination occurs. To combat this, farmer pre soak the seed in plain water for a few hours. But this may cause seed damage in more than one ways. Of them, major one is that, excess water may be trapped in the area of embryonic axis, nodal zone and cotyledons. This leads to suffocation, resulting in delayed and poor germination as well as weak seedling growth (Heydecker, 1977). Delayed and erratic germination create problems with fertilizer utilization, post emergence weed control, and uniform harvesting (Standifer et al., 1989). In recent times various seed quality enhancement treatments are given to the seeds as a pre-sowing treatment. The hard seed coat of chili is also a major physiological constraint to uniform stand establishment and performance.

\footnotetext{
${ }^{1}$ Executive Director, Bangladesh Science Foundation, Uttara, Dhaka-1230.

${ }^{2}$ Executive Director, Tista Environment Development Foundation, Rangpur.

${ }^{3}$ Upazilla Agriculture Officer, Fulpur, Mymensingh.
} 
Trichoderma genus is often the predominant components of the mycoflora in soils of various ecosystems, such as agricultural fields, prairie, forest, salt marshes and deserts, in all climatic zones (Harman, 2000a; Smith, 1995). It has capacity of controlling some plant and crop disease (Samuels, 1996). Trichoderma spp. on roots increases uptake of nitrates and other ions. And many also increase uptake of various toxic metals and metalloids (Harman, 2000b). Trichoderma strains are always associated with plant roots and root ecosystems. Some authors have defined Trichoderma strains as plant symbiont opportunistic avirulent organisms, able to colonize plant roots by mechanisms similar to those of mycorrhizal fungi and to produce compounds that stimulate growth and plant defense mechanisms (Harman et al., 2004). Root colonization by Trichoderma strains frequently enhances root growth and development, crop productivity, resistance to abiotic stresses and the uptake and use of nutrients (Arora et al., 1992). Crop productivity in fields can increase up to $30 \%$ after the addition of Trichoderma hamatum or Trichoderma koningii (Benítez et al., 2004). In experiments carried out in greenhouses, there was also a considerable yield increase when plant seeds were previously treated with spores from Trichoderma (Chet et al., 1997). The same increase was observed when seeds were separated from Trichoderma by a cellophane membrane, which indicates that Trichoderma produces growth factors that increased the rate of seed germination (Benítez et al., 1998). Trichoderma also compete with other microorganisms; for example, they compete for key exudates from seeds that stimulate the germination of propagules of plant-pathogenic fungi in soil (Howell, 2002) and more generally, compete with soil microorganisms for nutrients and/or space (Elad, 1996). Trichoderma strains that produce cytokinin-like molecules, e.g. zeatyn and gibberellin GA3 or GA3-related have been recently detected. The controlled production of these compounds could improve biofertilization (Osiewacz, 2002). Together with the synthesis or stimulation of phytohormone production, most Trichoderma strains acidify their surrounding environment by secreting organic acids, such as gluconic, citric or fumaric acid (Gómez-Alarcón and de la Torre, 1994). These organic acids result from the metabolism of other carbon sources, mainly glucose, and, in turn, are able to solubilize phosphates, micronutrients and mineral cautions including iron, manganese and magnesium (Harman et al., 2004). Moreover, recent studies have indicated that these fungi also induce localized or systemic resistance systems in plants (Yedidia et al., 1999; Howell, 2003). Thus, the variety of effects indicates that these beneficial fungi have multiple modes of action. Therefore, this study was design to find out the effect of different Trichoderma strains on the germination percentage rate and seedling parameters of chili seeds both in laboratory and field conditions.

\section{MATERIALS AND METHODS}

\section{Sources of Trichoderma strains}

Five Trichoderma strains viz. T. virens IMI-392430, T. pseudokoningii IMI-392431 and T. harzianum IMI-392432, T. harzianum IMI-392433 and T. harzianum IMI-392434 were used in this study which was collected from Biotechnology and Microbiology Laboratory, Department of Botany, Rajshahi University, Bangladesh. These strains were isolated and identified from decomposed garbage and soil by Rahman (2009) and were verified by CABI Bioscience, Surrey, U.K.

\section{Spore suspension preparation of Trichoderma strains}

Mycelial disc (1.2 cm diam.) of Trichoderma strains were obtained from 4-5 days-old culture and transferred to $50 \mathrm{ml} \mathrm{PDA}$ in a $250-\mathrm{ml}$ conical flask separately incubated at $28^{\circ} \mathrm{C}$ for $4-5$ days. At the end of the incubation period $30 \mathrm{ml}$ of sterile distilled water was added to each culture flask and the 
flasks were shaken at $50 \mathrm{rpm}$ for $30 \mathrm{~min}$ in an orbital shaker. Then the content of each conical flask was filtrate through sterile muslin cloth. The filtrate with the spores was collected and a concentration of spore suspension was adjusted to $5 \times 10^{5}$ conidia/ml by use of a hemacytometer under a light microscope.

\section{Seed selection and treatment}

The seed of chili Varity Bogra Local was used and collected from Spice Research Centre, Bogra, Bangladesh. The chili seeds were one year old and had been stored at $5^{\circ} \mathrm{C}$. Standard germination of the seeds was $98 \%$. Seeds with no cracks or other visible deformations were selected and surface sterilized for 10 minutes with1 \% sodium hypochlorite solution. Seeds were then rinsed three times with sterile distilled water and air dried. A seed coating was prepared from spore suspension supplemented with $2 \%$ of starch (w/v) as an adhesive. Dry chili seeds were dipped in seed coating suspension $\left(5 \times 10^{5}\right.$ spores $\left./ \mathrm{ml}\right)$ for each Trichoderma strains for 1-2 minutes. For untreated control seeds were dipped in $2 \%$ starch suspension and for water control seeds were dipped in sterilized distilled water. Seeds were air dried inside the laminar air flow hood. For in vitro experiment, treated seeds were placed in Petri plate's lines with two layers of Whatman filter paper soaked in sterilized distilled water and incubated at $25{ }^{\circ} \mathrm{C}$ under dark condition and for field experiment, treated seeds were sown separately in pot soils where the soil was previously inoculated with respective Trichoderma strains $\left(5 \times 10^{5}\right.$ spore $\left./ \mathrm{ml}\right)$ and for control treatment, treated seeds (treated with $2 \%$ starch and water) were sowing un inoculated soil in pot. At least ten seeds were sown in each pot. Seed germination percentages and vigour index was recorded after 3 to 8 days. Vigour index for each treatment was determined using the following formula developed by Abdul-Baki and Anderson (1973).

Vigour index $=[$ Mean of root length $(\mathrm{cm})+$ Mean of shoot length $(\mathrm{cm})] \times$ percentages of seed germination.

\section{Collection and preparation of soil for field experiment}

For field experiment soil was collected from the Field Laboratory of Plant Pathology Division, BARI, Gazipur and sterilized with Formaldehyde (Formalin: Water; 1:5 V/v). After 30 days of sterilization, soils were put in the earth pot of 12 inches height and 8 inches wide. For minimize losses of excess water $2 \mathrm{~cm}$ hole was made from the bottom of the pot.

\section{Experimental design and data analysis}

All experiments were established as a randomized block design with four replicates and ten chili seeds were used in each replicates. Data on germination percentages and vigour index were recorded after 3 to 8 days and statistically analyzed with the help of computer package program SPSS (SPSS Inc., Chicago, IL, USA) and also tested by DMRT.

\section{RESULTS AND DISCUSSION}

The effect of five Trichoderm strains on seed germination and seedling parameters of chili both in laboratory and field conditions the results are presented in Fig 1-8. Statistical analysis of figure showed significant differences in treatments at $\mathrm{P} \leq 0.05$ levels. Results showed that all Trichoderma strains were found effective to enhance the germination percentage compared to control. However among the five Trichoderma strains, T. harzianum IMI 392432 exhibited significantly enhancement of germination percentage in chili seeds both in laboratory and field conditions followed by $T$. harzianum IMI 392433, T. harzianum IMI 392434, T. virens IMI 392430 and T. pseudokoningii IMI 392431 (Fig 1 and 5), while control (treated with $2 \%$ starch and water) significantly decreased these values. This strains also showed earliest highest seed germination (100\%) at five and six days compared to the control both laboratory and field conditions, respectively. In controls (treated with $2 \%$ starch and water), both laboratory and field conditions showed worst germination percentage and vigour index. 
Some landmarks along the way include the discoveries that these fungi frequently increase plant growth and productivity (Harman, 2006; Manju and Mall, 2008). In this study, five Trichoderma strains gave early germination as well as highest germination percentage which have also been reported by many workers in different plants (Hanson, 2000; Mishra and Sinha, 2000; Oyarbide et al., 2001) and numerous other species such as $T$. longipile and $T$. tomentosum have been shown to promote plant growth (Rabeendran et al., 2000).Studies have been confirmed in case of $T$. harzianum and T. viridi to enhanced seed germination root and shoot length (Dubey et al., 2007) as well as increasing the frequency of healthy plants, and boosting yield (Rojoa et al., 2007). In a similar study Chaur-Tsuen Lo and Chien-Yih Lin (2002) screened Trichoderma strains on plant growth and root growth of bitter gourd, loofah and cucumber and noted that Trichoderma strains significantly increased of 26 to $61 \%$ in seedling height, $85-209 \%$ in root exploration, $27-38 \%$ in leaf area and 38 to $62 \%$ in root dry weight after 15 days of sowing. Methanol extract of T. harzianum and T. viridi significantly improved various growth parameters of okra (Prasad and Anes, 2008). Vigour index (VI) was also significantly affected by the application of different Trichoderma strains both in laboratory and field conditions (Fig 4 and 8). The results related to vigour index showed similar differences as in germination percentages. Seed treatment with Trichoderma strains increased vigour index compared to control. The highest VI values were recorded both in laboratory and field conditions when the chili seed were treated with T. harzianum IMI 392432. The lowest vigour index was recorded in control. Mukhtar (2008) investigated that seed treatment with T. harzianum gave the highest germination index in okra and T. harzianum can be useful to enhance the germination percentage as well as reduce lose due to delayed germination of okra seeds. Begum et al. (2010) were evaluated five Trichoderma strains to assay their efficacy in suppressing Alternaria fruit rot disease of chili and promoting chili plant growth and yield and observed that application of T. harzianum IMI 392432 significantly suppressed the disease and improved highest seed germination percentage, vigour index, growth and yield. Other investigators have also reported that seeds pretreated with T. viride, T. harzianum and $T$. pseudokoningii inoculant extracts, showed the increased seed germination rates, seedling vigour and reduced the incidence of seed-borne fungal pathogens compared to control (Zheng and Shetty, 2000; Bharath et al., 2006). The present study concludes that Trichoderma species have potential to enhance the germination in chili seeds which can be useful to enhance the germination percentage of chili seeds besides reducing loses due to delayed germination. Further investigations are required to study in vivo, effects of these fungi on the morphological and physiological characteristics in chili plant and fruit production.

\section{REFERENCES}

Abdul-Baki A, Anderson JD.1973. Vigour determination of Soyabean seed by multiple criteria. Crop Sci13, 630-633.

Anonymous 2003. Monthly Statistical Bulletin, Bangladesh. Bangladesh Bureau of Statistics, August 2003. p 54.

Arora, D. K., Elander, R. P.; Mukerji, and K. G. (eds) (1992). Handbook of applied mycology. Fungal Biotechnology, vol 4. Marcel Dekker, New York.

Begum, M. F.; Rahman, M. A. and Alam, M. F. (2010) Biological control of Alternaria fruit rot of chili by Trichoderma species under field conditions. Mycobiology 38 (2):113-117.

Benítez, T.; Delgado-Jarana, J.; Rincón, A M.; Rey, M. and Limón, M.C. (1998) Biofungicides: Trichoderma as a biocontrol agent against phytopatho-genic fungi. In: Pandalai SG (ed) Recent research developments in microbiology, vol. 2. Research Signpost, Trivandrum, pp 129-150 
Benítez, T; Rincón, A M. M.; Limón, C; Codón, A. C. (2004) Biocontrol mechanisms of Trichoderma strains. International Microbiology 7:249-260

Bharath, B.G.; Lokesh, S.; Prakash, H. S.; and Shetty, H. S. (2006) Evaluation of different plant protectants against seed mycoflora of watermelon (Citrullus lanatus). Res. J. Bot. 16:1-5.

Chaur-Tsuen, L. and Chien-Yih, L (2002) Screening strains of Trichoderma spp. for plant growth enhancement in Taiwan. Plant Pathology Bulletin 11:215-220

Chet, I; Inbar, J and Hadar, I (1997). Fungal antagonists and mycoparasites. In: Wicklow DT, Söderström B (eds) The Mycota IV: Environmental and microbial relationships. SpringerVerlag, Berlin, pp 165-184.

Dubey, S. C.; Suresha, M.; Singha, B. (2007) Evaluation of Trichoderma species against Fusarium oxysporum f. sp. ciceris for integrated management of chickpea wilt. Biological Control 40: 118-127.

Elad, Y. (1996) Mechanisms involved in the biological control of Botrytis cinerea incited diseases. Eur J Plant Pathol 102: 719-732

Gómez-Alarcón, G; and de la Torre, M. A (1994) Mecanismos de corrosion microbiana sobre los materiales pétreos. Microbiología 10:111-120.

Hanson, L. D. (2000) Reduction of Verticillium wilt symptoms in cotton following seed treatment with Trichoderma virens. J. Cotton. Sci. 4:224-231.

Harman, G.E.; Howell, C. R.; Viterbo, A.; Chet, I..; and Lorito, M. (2004). Trichoderma speciesopportunistic, avirulent plant symbionts. Nature Reviews 2:43-56.

Harman, G. E., (2000a). Trichoderma spp., including T. harzianum, T. viride, T. koningii, T. hamatum and other spp. Deuteromycetes, Monilialea (asexual classification system). Biological control: A guide to Natural Enemies in North America.

Harman, G. E. (2000b). Myths and digmas of biocontrol. Changes in perceptions derived from research on Trichoderma harzianum T-22. Pant Dis. 84:377-393.

Harman, G. E. (2006). Overview of mechanisms and uses of Trichoderma spp. Phytopathology.96:190-194.

Heydecker W. (1977). Stress and seed germination: and agronomic view. In the physiology and biochemistry of seed dormancy and germination, A. A Khan, ed. Amsterdam: North Holland Publishing Company.

Howell CR (2002) Cotton seedling preemergence damping-off incited by Rhizopus oryzae and Pythium spp. and its biological control with Trichoderma spp. Phytopathology 92: 177-180.

Howell CR (2003) Mechanisms employed by Trichoderma species in the biological control of plant diseases: The history and evolution of current concepts. Plant Dis., 87: 4-10.

Manju, S., and Mall, T.P. (2008) Efficacy of Trichoderma species on Phytopthora dresceleri f.sp. cajani of Pigeon pea. Ann. Plant Prot. Sci. 16:162-164.

Mishra, D.S., and Sinha, A.P. (2000) Plant growth promoting activity of some fungal and bacteria agents on rice seed germination and seedling growth. Tropical Agric. 77:188-191.

Mukhtar I (2008) Influence of Trichoderma species on seed germination in okra. Mycopath 6(1\&2): 47-50

Osiewacz HD (ed) (2002) Molecular biology of fungal development. Marcel Dekker, New York

Oyarbide, F., Osterrieth, M.L., and Cabello, M. (2001) Trichoderma koningii as a biomineralizing fungous agent of calcium oxalate crystals in typical Argiudolls of the Los Padres Lake natural reserve (Buenos Aires, Argentina). Microbiol. Res. 156:113-119.

Prasad, D., and Anes, K.M. (2008) Effect of metabolites of Trichoderma harzianum and T. viride on plant growth and meloidogyne incognita on okra. Ann. Plant Prot. Sci. 16:461-465.

Rabeendran, N, Moot, D. J., Jones, E. E., and Stewart, A. (2000) Inconsistent growth promotion of cabbage and lettuce from Trichoderma isolates. New Zealand Plant Prot.53:143-146. 
Rahman, M.A. (2009) Screening of Trichoderma spp. and their efficacy as a bio conversion agent of municipal solid waste through appropriate technique of solid state fermentation. $\mathrm{PhD}$ Thesis. Department of Botany, University of Rajshahi, Rajshahi-6205, Bangladesh.

Rojoa, F. G., Reynosoa, M.M., Fereza, M., Chulze, S.N. and Torres, A. M. (2007) Biological control by Trichoderma species of Fusarium solani causing peanut brown root rot under field conditions. Crop Prot. 26:549-555.

Samuels, G. J. (1996). Centenary Review, Trichoderma: A review of biology and systematic of genus. Mycol Res. 100 (8): 923-935.

Smith, W. H. (1995). Forest occurrence of Trichoderma species: Emphasis on potential organo chlorine (xenobiotic) degradation. Ecotoxico Environ Saf. 32: 179-183.

Standifer, L. C.; Wilson, P.W. and Drummond, A. (1989). The effects of seed moisture content on hardseededness and germination in four cultivars of okra [Abelmoschus sculentus (L.) Moench]. Plant Varieties Seeds, 2:149-154.

Yedidia, I.; Benhamou, N.; and Chet; I. (1999) Induction of defense responses in cucumber plants (Cucumis sativus L.) by the biocontrol agent Trichoderma harzianum. Appl. Environ. Microbiol., 65: 1061-1070.

Zheng, Z., and Shetty, K. (2000) Enhancement of pea (Pisum sativum) seedling vigour and associated phenolic content by extracts of apple pomace fermented with Trichoderma spp. Process Biochem. 36:79-84. 


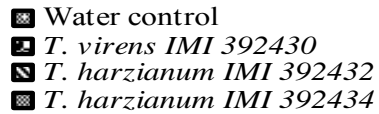

Adhesive control

T.pseudokoningii IMI 392431

部. harzianum IMI 392432

T. harzianum IMI 392433

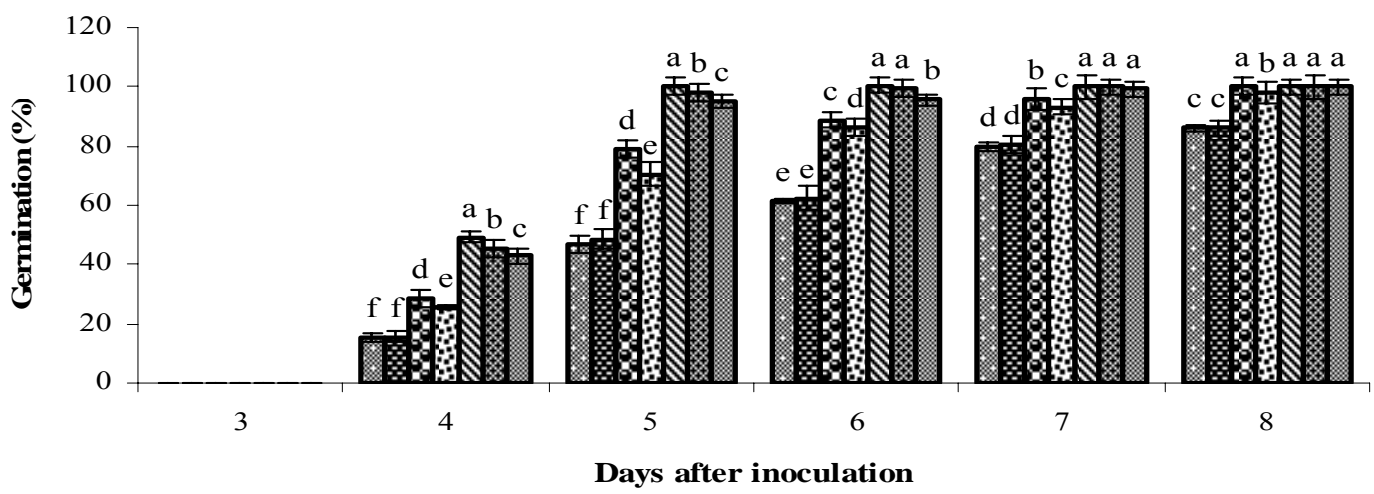

Fig 1. Effect of seed treatment with Trichoderma strains on the germination percentage of chili seeds in in vitro condition. Vertical bars show standard error of means of four replicates. Bar marked by the same letters are not significantly different $(\mathrm{P}<0.05)$ by DMRT analysis.

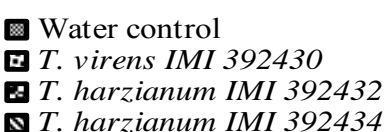

T. harzianum IMI 392434
Adhesive control

$\mathbf{v}$ T.pseudokoningii IMI 392431

凶 T. harzianum IMI 392433

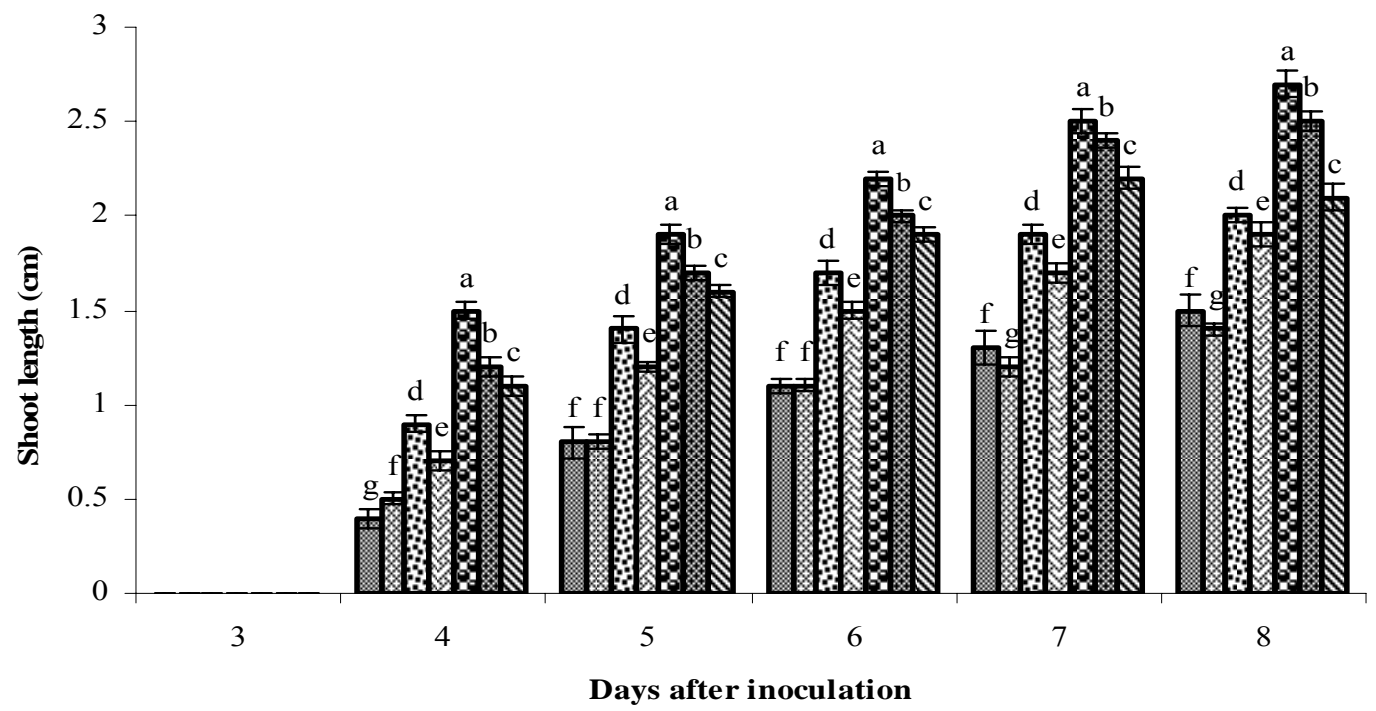

Fig 2. Effect of seed treatment with Trichoderma strains on shoot length of chili seeds in in vitro condition. Vertical bars show standard error of means of four replicates. Bar marked by the same letters are not significantly different $(\mathrm{P}<0.05)$ by DMRT analysis. 


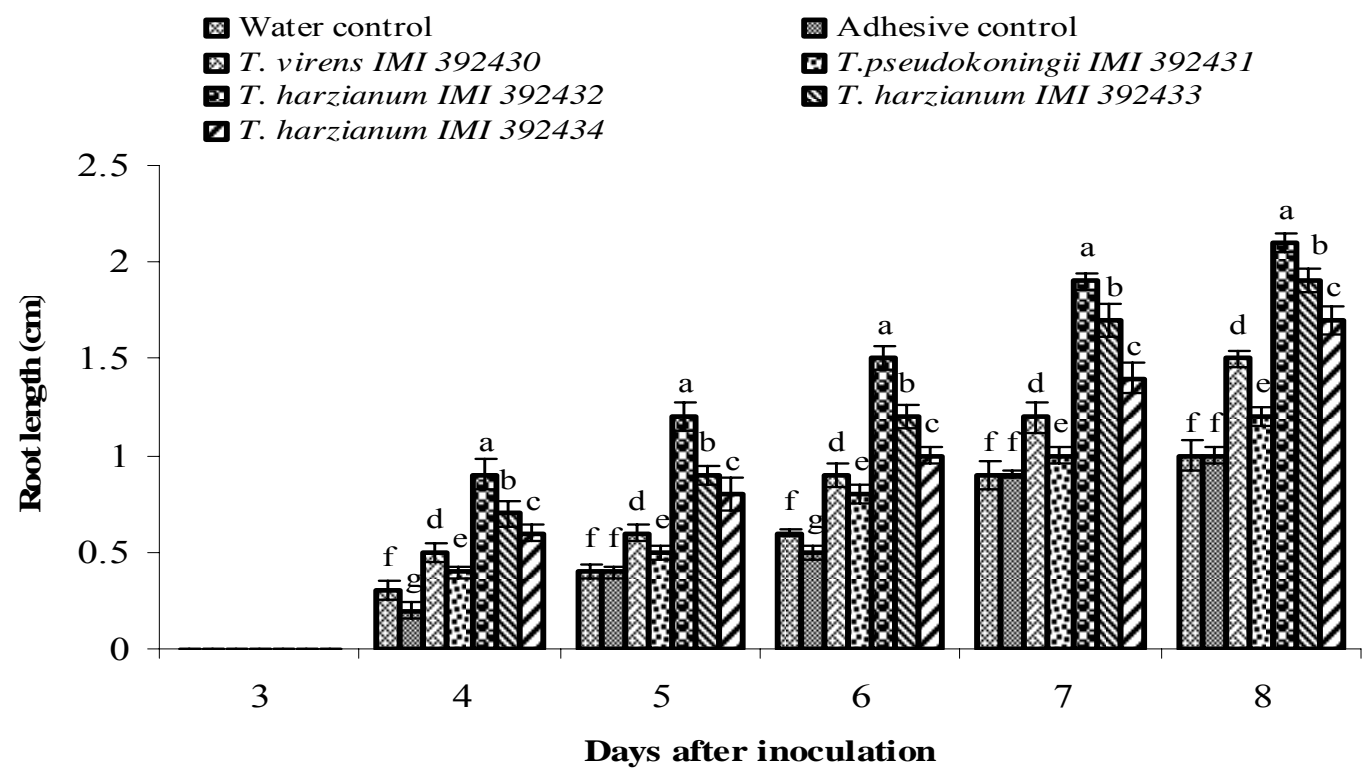

Fig 3. Effect of seed treatment with Trichoderma strains on root length of chili seeds in in vitro condition. Vertical bars show standard error of means of four replicates. Bar marked by the same letters are not significantly different $(\mathrm{P}<0.05)$ by DMRT analysis.
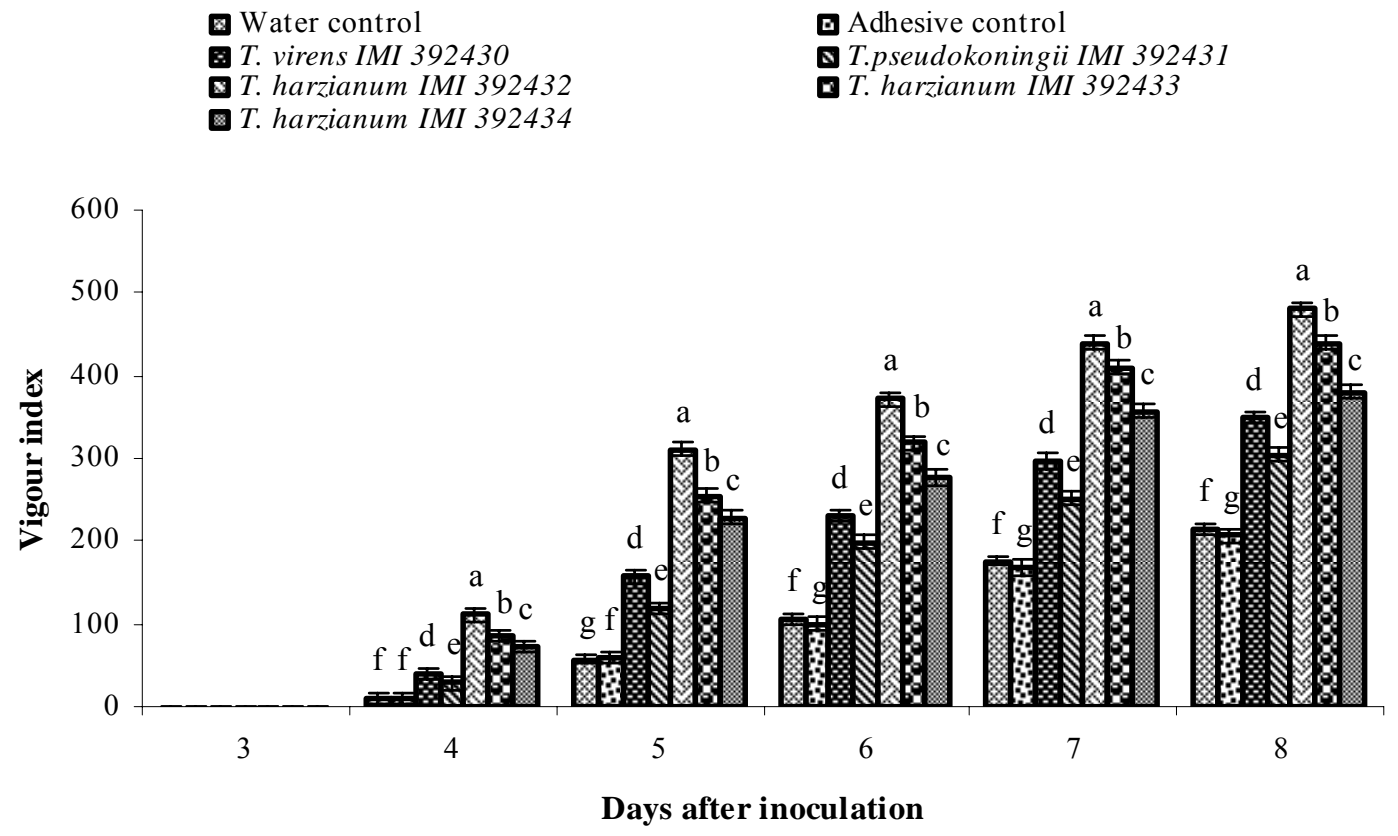

Fig 4. Effect of seed treatment with Trichoderma strains on vigour index of chili seeds in in vitro condition. Vertical bars show standard error of means of four replicates. Bar marked by the same letters are not significantly different $(\mathrm{P}<0.05)$ by DMRT analysis. 


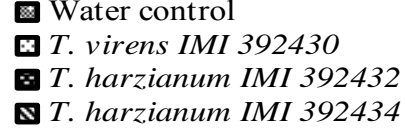

Adhesive control

ه T.pseudokoningii IMI 392431

T. harzianum IMI 392433

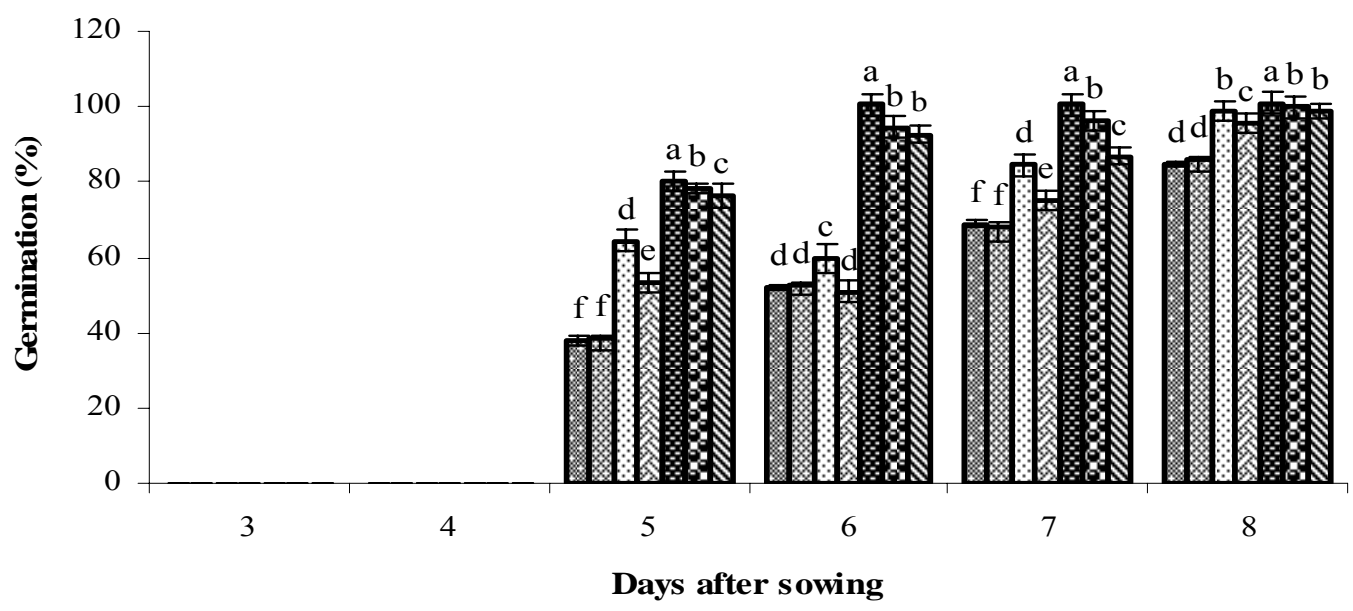

Fig 5. Effect of seed treatment with Trichoderma strains on the germination percentage of chili seeds in field condition. Vertical bars show standard error of means of four replicates. Bar marked by the same letters are not significantly different $(\mathrm{P}<0.05)$ by DMRT analysis.

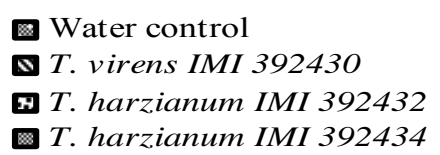

Adhesive control

« T.pseudokoningii IMI 392431

ॠ. harzianum IMI 392434

T. harzianum IMI 392433

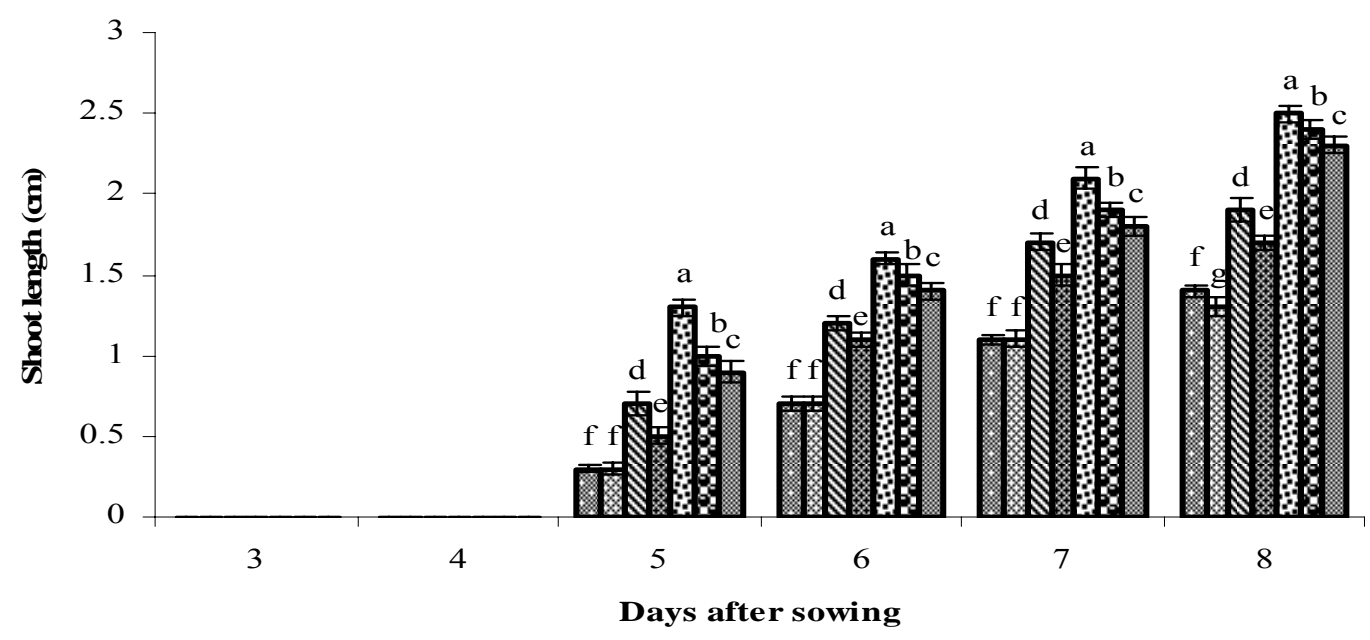

Fig 6. Effect of seed treatment with Trichoderma strains on the shoot length of chili seeds in field condition. Vertical bars show standard error of means of four replicates. Bar marked by the same letters are not significantly different $(\mathrm{P}<0.05)$ by DMRT analysis. 
중 Water control

T. virens IMI 392430

\$. harzianum IMI 392432

T. harzianum IMI 392434
Adhesive control

(t T.pseudokoningii IMI 392431

$\mathbf{x}$ T. harzianum IMI 392433

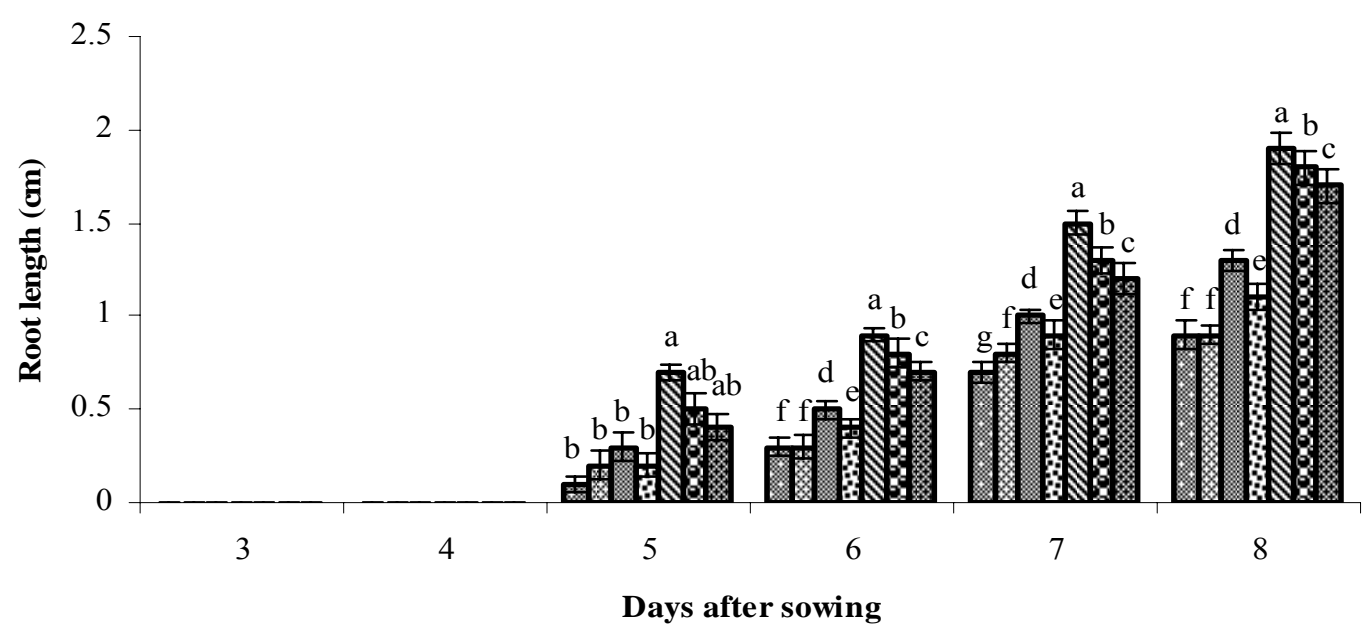

Fig 7. Effect of seed treatment with Trichoderma strains on the root length of chili seeds in field condition. Vertical bars show standard error of means of four replicates. Bar marked by the same letters are not significantly different $(\mathrm{P}<0.05)$ by DMRT analysis.

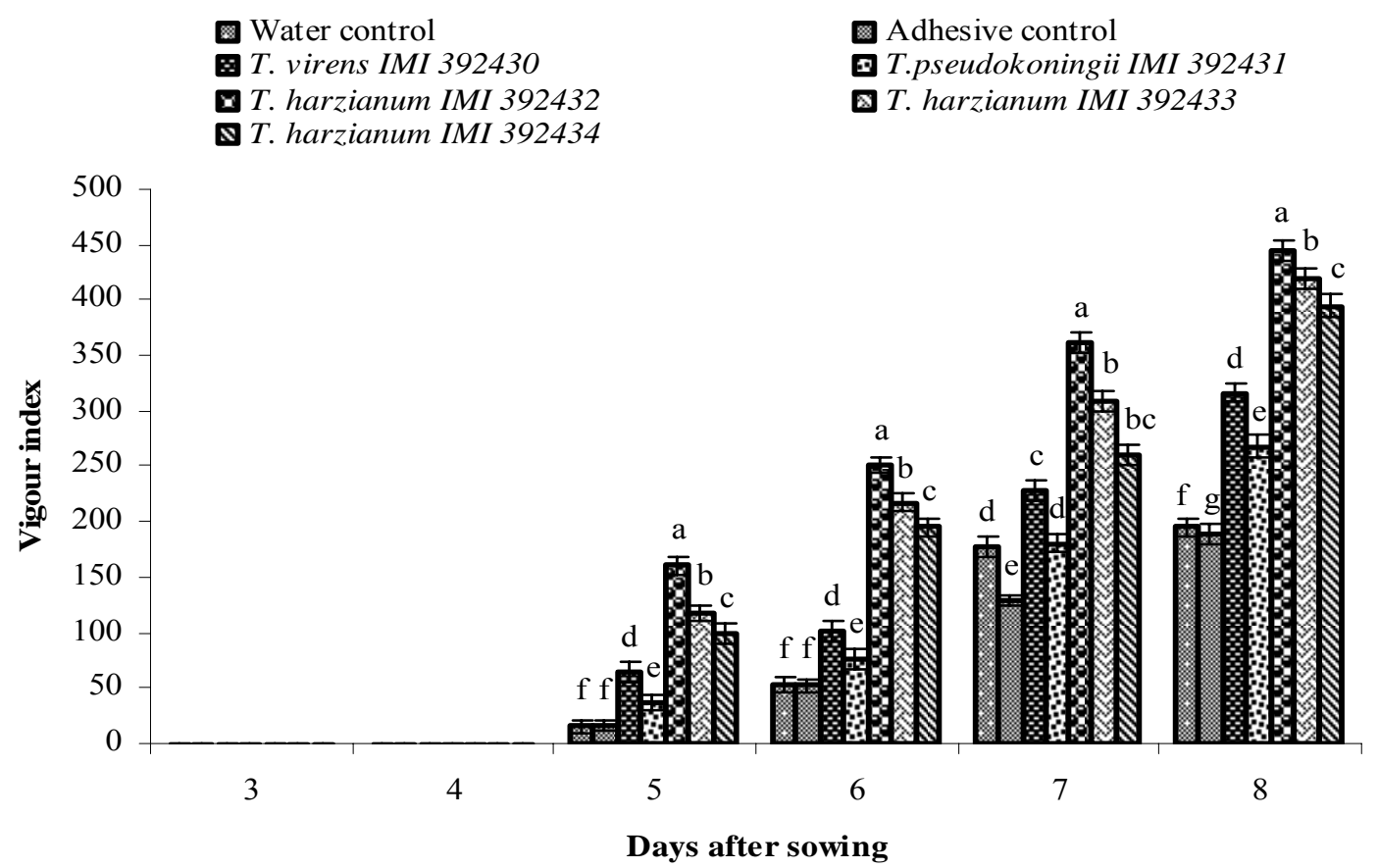

Fig 8. Effect of seed treatment with Trichoderma strains on the vigour index of chili seeds in field condition. Vertical bars show standard error of means of four replicates. Bar marked by the same letters are not significantly different $(\mathrm{P}<0.05)$ by DMRT analysis. 